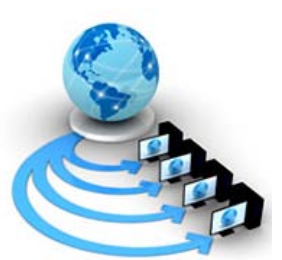

Volume 8, No. 9, November-December 2017

International Journal of Advanced Research in Computer Science

RESEARCH PAPER

Available Online at www.ijarcs.info

\title{
COMPARISON OF SOFTWARE TESTING TOOLS WITH RESPECT TO TOOLS AND TECHNICAL RELATED PARAMETERS
}

\author{
Dr.M.Kannan \\ Assistant Professor, Department of Computer Science \\ \& Applications \\ SCSVMV University, Enathur, \\ Kanchipuram-631561
}

\author{
K.Lokeshwari \\ M.Phil Research Scholar, Department of Computer \\ Science \& Applications \\ SCSVMV University, Enathur, \\ Kanchipuram-631561
}

\begin{abstract}
Software Testing is the series of actions to seeking the error defects in the software. It mean, probe carry with comprehensive information of the quality of software underneath the test. Software Testing tools allow the developer and tester to proceed the work in a way of effortlessly which gives the path as computerize practice of difficult in the software progress, Generally, testing arise as manual or automated where the comparison is passes between the expected results with the actual result, In these days, Automated Software testing is high ranking for software projects so as to naturally validate and verify numerous process of the project. The goal of this scrutiny is ti assess and reconcile the automated software testing tools such as QTP, Selenium and Load Runner to dig out their usability, performance, legibility. This study helps the developer and tester to select the apt tool depends on their needed.
\end{abstract}

Keywords: Manual Testing, Automated Testing, Qtp, Selenium, Load Runner

\section{INTRODUCTION}

Software testing is a most primary phase in software development cycle. Software testing action uses up most closely 40 to 70 percent of total time of software development process. The motive of software testing is to upgrade the overall quality of software by discovering all fault present in software. Software testing is a appliance that is used to appraise the functionality and validity of software. Software testing makes sure the good quality software that works to meet the demand of stakeholders.

Software testing is an approach to manipulate a testing process with the entire software process. Testing is a process of realize a program with the motive of seeking a mistake. Testing should strictly unveil different classes of errors in a minimum amount of time and with a minimum amount of effort. A second thing of benefit in testing is that it exhibit that the software become visible as disclose in the stipulation. The data gathered along testing can also provide an evidence of the software's reliability, quality, efficiency, usability and performance. But, testing cannot reveals the unpresence of faults it can only shows the faults which are presents in the software. Software testing is a very essential zone of research and a lot of enhancement has been made in this field.

\section{LITERATURE REVIEW}

Mohammad Imran, [1] et. al described the basics about testing and strategies of testing. This paper also evaluates and compares automated software testing tools such as qtp and load runner to determine their usability and effectiveness. There are various tools available that help software teams build and execute automated tests. But the major part in this paper is to select the effective tool among various categories of tools features such as application support, reports, software cost, script creation time and language, environment and browser supports. Finally they concluded as LoadRunner will be best with the application of lesser security whereas QTP is best where data security is required.

Krutika Kamble \& Jyoti Kharade [2] conducted a quantitative analysis of manual and automation testing and comparative study of automated tools such as load runner and selenium, and they classified the automated tools as functional testing tools, load testing tools and test management tools. Comparison purely done by the features of the tools such as license cost, script recorder, response time, multi-browser support and so on. In conclusion, mentioned as Selenium simulates user interaction with the interface whereas Load Runner simulates significant usage. Selenium simulates a user by recording its actions on the interface whereas Load Runner doesn't hassle concerning the interface and records the commands through a proxy. Selenium is mainly use for functional testing whereas Load Runner is use mainly for performance testing. Sanjeev Gupta [3] et. al, presented a comparative study of automated tools such as selenium and qtp. They mainly focused on project requirements and financial status to select the testing tools. Also they discussed about selenium and qtp frame work. Compared two tools with respect to cost, language and application support, file upload system and execution speed.

Amit P. Raut [4] et. al, conducted a survey on the testing tools. They discussed about when to start and when to stop testing. They represented the hierarchy of software testing and modes of testing such as manual testing and automated testing and their process. All tools are discussed thoroughly, showing the benefits and limitation of each tool.

Shalini Gautam \& Bharti Nagpal [5] organized a descriptive study on the testing tools and testing. The system specifications have discussed generally to evaluate the parameters. The phases of testing life cycle frame work have listed and levels of testing also discussed. The main 
objective of this paper is to the software testing tools by their uses and benefits. Finally they concluded as automation testing is more useful and time saving then the manual testing.

Priyanka Rathi \& Vipul Mehra [6] analyses have done on automation and manual testing by using testing tools. The comparison have made between manual and automated, by using qtp they analyzed benefits and its limitations. The categories for test and tools to make the testing very easy such as Developer oriented tools, Functional testing tools, Load testing tools, Performing ability and maintenance tools. This paper discussed some manual testing metrics and automation metrics like test execution, test case productivity, fault rejection metrics and test coverage metrics to make assess the performance of testing.

Rifa Nizam Khan \& Shobhit Gupta [7] discussed about the testing concepts and tools. The ethodology were discussed on automated software testing tools such as qtp, IBM Rational Functional Tester, silk test and load runner. The evaluation studies have conducted on the tools such as ensuring consistency, robust and high-performing. Some of features are considered to compare these tools such as recording efficiency, data driven testing, reusability, cost, easy to learn and speed. Finally concluded that qtp is good tool among the four.

R. Beulah and Dr. M. Soranamageswari [8] discussed about performance and comparative study of functionality testing tools such as win runner and qtp. Also discussed testing concepts and some skills sets good software tester such as diagnostic and logical skills, planning and scheduling skills, assume from customer view point and methodological skills. Some set of activites of test manager,test team and engineer have discussed. The differences between manual and automated have framed. Finally concluded qtp is the best tool than the win runner.

Mohamed Monier \& Mahmoud Mohamed El-mahdy [9] discussed about the web testing concepts and tools. The methodology has done on the tools such as selenium, qtp, sahi and ranorex. Comparison have made on these tools by using their features. The paper has evaluation study on the above mentioned tools according to their criteria which gives the knowledge how to select the tool based on the requirements.

Shaveta [10] et. al, discussed about on comparative study of automated tools such as qtp and load runner. Authors says, that the testing is a critical part of the software development process which need fulll attention to proceed the process; to handle those things, we need automated testing mechanism, which are the problem statement were identified. Evaluation study has been done to conduct the selection procees on the tool by comparison with the help of following, Record Efficiency, Capability of scripts generating, Data testing, Test reports generations, Reusability, Speed and Playback capacity, Cost. Each has five point scales from extremely good to average. Concluded as Load Runner will be the best to use for applications but having low security but QTP is best which provides data security in higher.

Preeti Yadav \& Ajay Kumar [11] has discussion on the selenium framework concepts. The basic selenium components have discussed, there are three versions of selenium, each can be merged to create the automation suite foe web applications they are Selenium IDE, Selenium Core, and Selenium RC and highlights pros and cons of
Selenium IDE. In conclusion, selenium is best framework for user interface of a web application. Purely automated is used to avoid the manual effort.

Tarik Sheth \& Dr. Santosh Kumar Singh[12]

discussion about the testing concepts and methodologies of automated software testing tools such as selenium, soap UI, qtp, test complete. Comparison between these four tools is made on the basis of different parameters. These can be record-playback capability, script generation capability, application and technical support, data capability, report generation capability, debugging support, license and training cost etc. In the conclusion they concluded, soap UI is the best among the four.

V. Maheshwari and M. Prasanna [13] discussed various test case generations for better testing approaches. P.Mani \& M.Prasanna [14] proposed UML based interaction diagram for test case generation.

\section{OBJECTIVES}

The objective of the study as follows,

$>$ To compare the three automated testing tools and assess the each tool accordingly. The tools are Selenium, QTP and Load Runner

$>$ To get the contradictory analysis of tools by using the various factor dimensions. The dimensions are Personal Information, Tools Related Factors and Technical Related Factors

$>$ To identify the significant factor dimensions on tools.

$>$ To test significant difference between selected tools with the parameters taken from tools related factors and technical related factors.

\section{METHODOLOGY}

The population of a study indicates that total number of people going to involve for obtaining the data.

In this research, totally 150 Population were framed from top MNC company's located in Chennai. From the population, randomly selected sample, the sample size is 100.The study implements only primary data in answering research questions. In order to obtain the data, questionnaire and interview methods were chosen.The survey questionnaire covered 3 main dimensions of basic information, tools related questionnaire, technical related questionnaire. All items and individual factors measured were adequately discussed under the literature review section of the study. The various dimensions were based on exploratory study to determine factors. A total of 10 items were placed under basic information dimension, 15 factors under tools related, and 15 factors under technical related dimensions which are taken from [15].

\subsection{PILOT STUDY}

A pilot study is a research study conducted before the intended study. Pilot studies are usually executed as planned for the intended study, but on a smaller scale.

Pilot studies assist in instituting measures and constraints, clarity of directives, and help to determine the right level of the independent variable. In all, 15 employees conveniently selected from top MNC Company were selected. After pilot study, questionnaire is fine tuned to meet the objectives. 


\subsection{FINAL DRAFT}

After the pilot study, few changes have made to frame the final draft of the questionnaire. In the questionnaire, the parameters have listed separately for as tools related factors and technical related factors which are taken from the BOEHM’s Quality Model [15].

\section{RESULTS AND CONCLUSION}

In this chapter, collected data are summarized and presented in the following sections. Section 5.1 depicts the demographic profile of the respondents, 5.2 shows the tools related parameters and technical related parameters, 5.3 shows the hypothesis testing to find the significant differences.

\subsection{Demographics for Personal Profile Table 5.1: Personal Profile}

\begin{tabular}{|c|c|c|}
\hline Variables & Category & Percentage \\
\hline Gender & $\begin{array}{l}\text { Male } \\
\text { Female }\end{array}$ & $\begin{array}{l}48 \\
52\end{array}$ \\
\hline Age & $\begin{array}{l}<25 \\
26-35 \\
>35 \\
\end{array}$ & $\begin{array}{l}40 \\
36 \\
24\end{array}$ \\
\hline Designation & $\begin{array}{l}\text { Testing Manager } \\
\text { Test Lead } \\
\text { Senior Tester } \\
\text { Technical Engineer } \\
\text { Designer }\end{array}$ & $\begin{array}{c}28 \\
34 \\
24 \\
6 \\
8 \\
\end{array}$ \\
\hline Project Domain & $\begin{array}{l}\text { Logistics } \\
\text { Tele } \\
\text { Communications } \\
\text { Retail Industry } \\
\text { Banking } \\
\text { Hospital } \\
\end{array}$ & $\begin{array}{l}10 \\
34 \\
22 \\
18 \\
16\end{array}$ \\
\hline $\begin{array}{l}\text { Total } \\
\text { Experience }\end{array}$ & $\begin{array}{l}<3 \\
3-6 \\
>6 \\
\end{array}$ & $\begin{array}{l}50 \\
28 \\
20 \\
\end{array}$ \\
\hline $\begin{array}{l}\text { Testing } \\
\text { Experience }\end{array}$ & $\begin{array}{l}<3 \\
3-6 \\
>6 \\
\end{array}$ & $\begin{array}{l}60 \\
20 \\
20 \\
\end{array}$ \\
\hline Current Tool & $\begin{array}{l}\text { QTP } \\
\text { Selenium } \\
\text { Load Runner }\end{array}$ & $\begin{array}{l}36 \\
50 \\
15 \\
\end{array}$ \\
\hline Testing Part & $\begin{array}{l}\text { Manual } \\
\text { Automated } \\
\text { Both } \\
\end{array}$ & $\begin{array}{l}42 \\
20 \\
38 \\
\end{array}$ \\
\hline $\begin{array}{ll}\text { Career } & \text { With } \\
\text { Testing } & \\
\end{array}$ & $\begin{array}{l}\text { Yes } \\
\text { No }\end{array}$ & $\begin{array}{c}94 \\
6 \\
\end{array}$ \\
\hline $\begin{array}{l}\text { Growth with } \\
\text { Tool }\end{array}$ & $\begin{array}{l}\text { Yes } \\
\text { No }\end{array}$ & $\begin{array}{c}98 \\
2\end{array}$ \\
\hline $\begin{array}{l}\text { Satisfied } \\
\text { Designation }\end{array}$ & $\begin{array}{l}\text { Yes } \\
\text { No }\end{array}$ & $\begin{array}{c}94 \\
6\end{array}$ \\
\hline
\end{tabular}

Source: Primary data

Out of data collected with the help of the questionnaire, 52\% are Female and $48 \%$ are Male. When consideration on Age most of the Employees were lesser 25 years (40\%) and the age between 26 to 35 years are about next higher (36\%) and greater 35 years (24\%).From the table 5.1, most of the workers were from Testing (85\%), a few others from Developer(also act as Tester 15\%), that is, Test Lead (34\%) and Testing
Manager (28\%) were majority and next place is Senior Tester(24\%) and few from Technical Engineer(6\%) and Designer(8\%).

From the table 5.1, according to project domain most of the Respondents from Tele communications (34\%), many of the Respondents interviewed were from mid center of IT, such as logistics (10\%), retail industry (22\%), banking (18\%), and hospital (16\%).

From the table 5.1, the respondents from total experience factor is higher for lesser than 3 years experience (50\%), and the total experience between 3 to 6 years is few (28\%), and the most experience persons that is, having experience greater 6 years are participated only $20 \%$.From the table 5.1, considering about testing experience the respondents from lesser 3 years is higher most that is 60\% respondent from Total Testing Experience factor and few higher for total experience between 3 to 6 years is few (20\%) and the lesser than 3 years experience (20\%).From the table 5.1, The essential factor current tools gives the exact status of respondent suggestions, the tool QTP has the responsive by 36\% and the Selenium has received the higher responsive (50\%) and the Load Runner(15\%) received only few lesser than qtp and selenium. From the table 5.1, the factor career growth with testing is one of the essential considerations by the respondents, because which has the power to decide them growth in career. The responsive rate for this factor is yes (94\%), that is they having growth by learning and working with it and few says no (6\%), which means not having growth.The factor growth with tool is one of the essential considerations by the respondents, because which has the power to decide them growth in career. The responsive rate for this factor is yes (98\%), that is they having growth by learning and working with it and few says no (2\%), which means not having growth.The another important factor is satisfied designation, for this from the respondents, we received yes (94\%) and no (6\%) which means not satisfied.

\subsection{Mean Value Analysis for Testing Tools: QTP, Selenium and Load Runne \\ 5.2.1 Tools Related Parameters.}

The below table shows the mean difference between the factors which are comes under the tools related parameters. Only the essential factors are picked and discussed here. They are quality, platform support, efficiency, performance, accessibility, organization support, and cost.

Table 5.2: Tools Related Parameters

\begin{tabular}{|l|l|c|}
\hline Factors & Tools & Mean \\
\hline Quality & QTP & 3.56 \\
& Selenium & 4.44 \\
& Load Runner & 3.57 \\
\hline Platform Support & QTP & 3.78 \\
& Selenium & 4.60 \\
& Load Runner & 3.86 \\
\hline Consistency & QTP & 4.11 \\
& Selenium & 4.28 \\
& Load Runner & 4.00 \\
\hline Efficiency & QTP & 3.44 \\
& Selenium & 3.80 \\
& Load Runner & 3.29 \\
\hline Usability & QTP & 4.06 \\
& Selenium & 4.04 \\
\hline
\end{tabular}




\begin{tabular}{|c|c|c|}
\hline & Load Runner & 3.43 \\
\hline Performance & $\begin{array}{l}\text { QTP } \\
\text { Selenium } \\
\text { Load Runner }\end{array}$ & $\begin{array}{l}4.00 \\
4.04 \\
4.00\end{array}$ \\
\hline Reliability & $\begin{array}{l}\text { QTP } \\
\text { Selenium } \\
\text { Load Runner }\end{array}$ & $\begin{array}{l}2.94 \\
3.92 \\
4.43\end{array}$ \\
\hline Robustness & $\begin{array}{l}\text { QTP } \\
\text { Selenium } \\
\text { Load Runner }\end{array}$ & $\begin{array}{l}3.89 \\
4.04 \\
4.00 \\
\end{array}$ \\
\hline Accessibility & $\begin{array}{l}\text { QTP } \\
\text { Selenium } \\
\text { Load Runner }\end{array}$ & $\begin{array}{l}4.06 \\
4.32 \\
4.00\end{array}$ \\
\hline $\begin{array}{l}\text { Organization } \\
\text { Support }\end{array}$ & $\begin{array}{l}\text { QTP } \\
\text { Selenium } \\
\text { Load Runner }\end{array}$ & $\begin{array}{l}3.89 \\
4.88 \\
3.89\end{array}$ \\
\hline Legibility & $\begin{array}{l}\text { QTP } \\
\text { Selenium } \\
\text { Load Runner }\end{array}$ & $\begin{array}{l}4.00 \\
4.20 \\
3.71 \\
\end{array}$ \\
\hline Product Support & $\begin{array}{l}\text { QTP } \\
\text { Selenium } \\
\text { Load Runner }\end{array}$ & $\begin{array}{l}4.17 \\
4.28 \\
3.57 \\
\end{array}$ \\
\hline $\begin{array}{l}\text { Framework } \\
\text { Complexity }\end{array}$ & $\begin{array}{l}\text { QTP } \\
\text { Selenium } \\
\text { Load Runner }\end{array}$ & $\begin{array}{l}3.89 \\
4.40 \\
3.57 \\
\end{array}$ \\
\hline Cost & $\begin{array}{l}\text { QTP } \\
\text { Selenium } \\
\text { Load Runner }\end{array}$ & $\begin{array}{l}3.61 \\
4.60 \\
3.71\end{array}$ \\
\hline $\begin{array}{l}\text { Platform } \\
\text { Dependency }\end{array}$ & $\begin{array}{l}\text { QTP } \\
\text { Selenium } \\
\text { Load Runner }\end{array}$ & $\begin{array}{l}3.94 \\
4.24 \\
3.71\end{array}$ \\
\hline
\end{tabular}

Source: Primary data]

\section{Quality}

From the table 5.2, for the every product has specified quality only based on this, the market of the product decides by this factor. In the tool selection, the respondent says major support to the quality. Here we received higher support to the selenium with the mean 4.44.With the comparison to qtp and load runner tool, the selenium received highest mean support from the respondents.

\section{Platform Support}

Once the product has decided to run or execute in the system, the very important thing we need to notify about platform support. Most of respondent suggestions were to consider about this factor. In the Table 5.2, this factor gives major credit mean 4.60 to selenium, not much to Qtp and Load Runner.

\section{Efficiency}

The ratio of the useful work performed by a tool or in a process to the total power expended which act as main factor to select a tool. The respondents gave very huge responses to selenium, the mean 3.80 which is in table 5.2

\section{Performance}

For the every software product the factor performance gives its higher potential rate to buy and to use. In this basis we received huge support to selenium, the mean value 4.04 from table 5.2.

\section{Accessibility}

For every software accessing is very essential to be considered for the further usage. The factor Accessibility got maximum higher rate for selenium, the mean 4.32 mentioned in the table 5.2.

\section{Organization Support}

The factor Organization Support plays a major role in the organization while selecting the tool. The respondent gives higher for selenium, the mean 4.88 .

\section{Cost}

Another higher rate factor is cost, the respondents gives higher most rate to selenium, the mean value is 4.60 from table 5.2 .

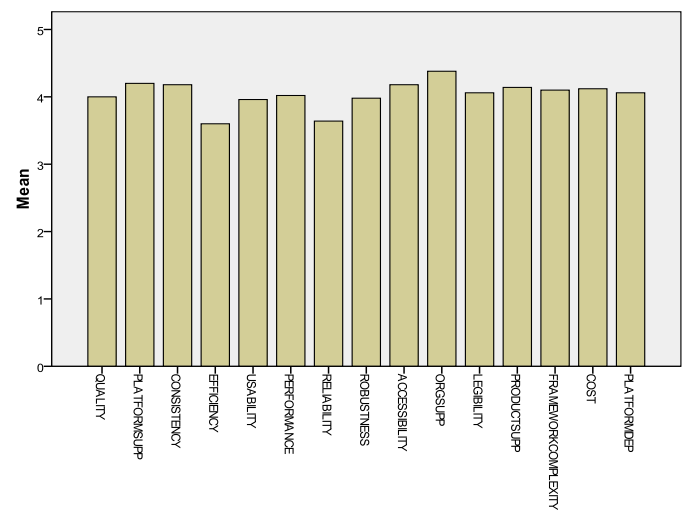

Fig 5.1 Mean Value : Tools Factors

\subsubsection{Technical Related Parameters}

The below table 5.3, Fig.5.2 shows the mean difference between the factors which are comes under the technical related parameters. Only the essential factors are picked and discussed here. They are accuracy, application support, performance, speed, script generation and results generation.

Table 5.3: Technical Related Parameters

\begin{tabular}{|l|l|c|}
\hline Factors & Tools & Mean \\
\hline Accuracy & QTP & 3.78 \\
& Selenium & 4.60 \\
& Load Runner & 4.00 \\
\hline Security & QTP & 3.83 \\
& Selenium & 4.48 \\
& Load Runner & 4.71 \\
\hline Support to all & QTP & 4.17 \\
kind of system & Selenium & 4.04 \\
& Load Runner & 4.43 \\
\hline Application & QTP & 3.83 \\
Support & Selenium & 3.92 \\
& Load Runner & 3.43 \\
\hline Performance & QTP & 3.83 \\
& Selenium & 4.68 \\
& Load Runner & 3.71 \\
\hline Efficiency & QTP & 3.78 \\
& Selenium & 4.64 \\
& Load Runner & 4.14 \\
\hline Programming & QTP & 3.89 \\
Language & Selenium & 4.16 \\
Support & Load Runner & 4.43 \\
\hline
\end{tabular}




\begin{tabular}{|l|l|l|}
\hline Debugging & QTP & 4.22 \\
Support & Selenium & 4.12 \\
& Load Runner & 3.86 \\
\hline Speed & QTP & 3.78 \\
& Selenium & 4.80 \\
& Load Runner & 4.14 \\
\hline Script & QTP & 4.11 \\
Reusability & Selenium & 3.84 \\
& Load Runner & 4.00 \\
\hline Script & QTP & 3.61 \\
Generation & Selenium & 4.24 \\
& Load Runner & 3.86 \\
\hline Test Data & QTP & 3.83 \\
& Selenium & 4.20 \\
& Load Runner & 3.86 \\
\hline Record & and & 4.11 \\
Playback & Selenium & 3.96 \\
& Load Runner & 4.43 \\
\hline Support with & QTP & 4.06 \\
Data Base & Selenium & 4.12 \\
& Load Runner & 4.14 \\
\hline Result & QTP & 4.11 \\
Generation & Selenium & 4.16 \\
& Load Runner & 3.71 \\
\hline
\end{tabular}

Source: Primary data

\section{Accuracy}

The factor accuracy plays a major role in selecting the appropriate tool. Only the tools outcome is depend on actual and existing results. The respondents give the major suggestions to selenium by the mean values differences mean 4.60, which is mentioned in the table 5.3.

\section{Application Support}

So many tools are available in the markets, but not every tool is used for all kind of projects, which is purely based on the characteristics of the application or project. Our respondents gives perfect match of support is selenium with the mean value difference mean 3.92 refer the table 5.3.

\section{Performance}

For the every software product the factor performance gives its higher potential rate to buy and to use. In this basis we received huge support to selenium, the mean values is 4.68 in table 5.3 .

\section{Speed}

Respondent gives the major rate to selenium with the mean value difference by comparing with qtp and load runner, mean 4.80 .

\section{Script Generation}

For every test case generation there should be script and which will be maintained by a separate database. Huge credit it given to selenium with respect to mean 4.24.

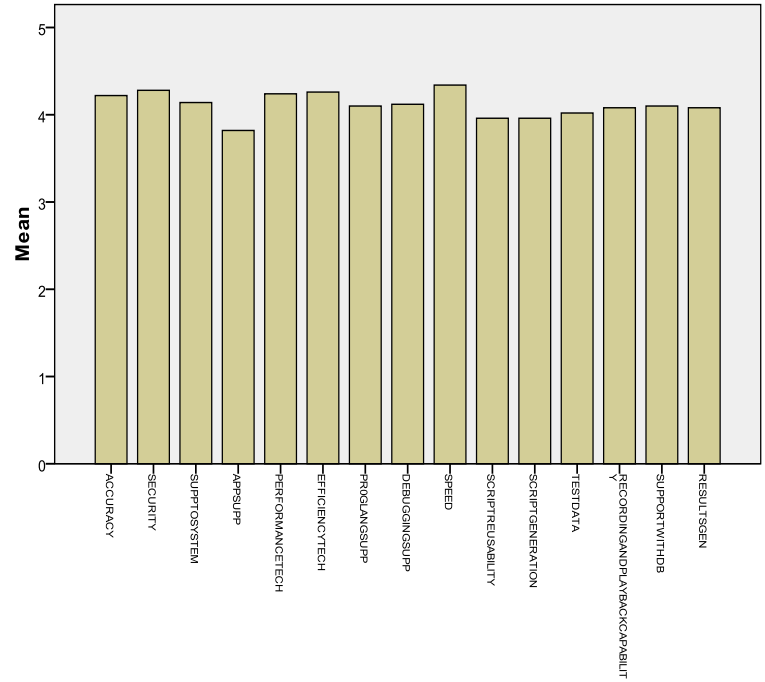

Fig 5.2 Mean Values : Technical Related Factors

\subsection{ANOVA Analysis}

\subsubsection{Hypothesis 1}

$\mathrm{H}_{0}$ : No Significant difference between currently using tool with respect to tools related parameters.

$\mathrm{H}_{\mathrm{a}}$ : There is significant difference between currently using tool with respect to tools related parameters.

Table 5.4 ANOVA for Tools Related Factors

\begin{tabular}{|l|c|}
\hline Variable & Significant Differences \\
\hline Quality & 0.024 \\
\hline Platform support & 0.047 \\
\hline Consistency & 0.713 \\
\hline Efficiency & 0.428 \\
\hline Usability & 0.265 \\
\hline Performance & 0.991 \\
\hline Reliability & 0.006 \\
\hline Robustness & 0.870 \\
\hline Accessibility & 0.579 \\
\hline Organization support & 0.001 \\
\hline Legibility & 0.404 \\
\hline Product support & 0.202 \\
\hline Framework complexity & 0.113 \\
\hline Cost & 0.003 \\
\hline Platform Dependency & 0.411 \\
\hline
\end{tabular}

Source: Primary data

From the above table 5.4, it is observed that significant value for the factors such as quality, platform support, efficiency, reliability, organization support, and cost is less than $<0.05$,hence, null hypothesis is rejected and alternate hypothesis is accepted.

5.3.2 Hypothesis 2

$\mathrm{H}_{0}$ : No Significant difference between currently using tool with respect to tools related parameters.

$\mathrm{H}_{\mathrm{a}}$ : There is significant difference between currently using tool with respect to tools related parameters. 
Table 5.5: ANOVA for Technical Related Factors

\begin{tabular}{|l|l|}
\hline Variables & $\begin{array}{l}\text { Significant } \\
\text { Differences }\end{array}$ \\
\hline Accuracy & 0.027 \\
\hline Security & 0.015 \\
\hline Support to all kind systems & 0.589 \\
\hline Application Support & 0.566 \\
\hline Performance & 0.004 \\
\hline Efficiency & 0.005 \\
\hline $\begin{array}{l}\text { Programming } \\
\text { Language support }\end{array}$ & 0.412 \\
\hline Debugging Support & 0.778 \\
\hline Speed & 0.003 \\
\hline Script Reusability & 0.755 \\
\hline Script Generation & 0.190 \\
\hline Test Data & 0.495 \\
\hline Recording and Playback & 0.542 \\
\hline Support with Database & 0.970 \\
\hline Result Generation & 0.632 \\
\hline
\end{tabular}

Source: Primary data

From the above table 5.5, it is observed that significant value for the factors such as Accuracy, Security, Performance, Efficiency and Speed is less than $<0.05$, hence, null hypothesis is rejected and alternate hypothesis is accepted.

\section{CONCLUSION}

One can select an automated testing tool depends on the application type. For every projects the tool should need to be tested, efficiency, and budget. The Automated Software Testing tools are very high expenses so the software companies will decided to go with manual testing, but manual testing are not efficiency, accuracy and takes time consumption when compare to automation testing. To deliver the software projects as quality and accuracy and so on which are only done by automation testing. Automation testing is appropriate than the manual testing, which means the manual testing will not give importance for precision value. By using Automation, out coming of the projects are very qualities, increasing the test execution speed, get more reliable and reusable are in Recording, play back of scripts, and test bulk of test case. This study analyzes three tools namely Selenium, Qtp, Load Runner. Selenium and Load Runner are both effective tools for automation testing. These three has significant difference by mean value. The highest among the three is Selenium. Selenium for tools related factors are 64.08 and technical related factors are 63.96, Qtp for tools related factors are 57.34 and technical related factors are 58.94 and Load Runner for tools related factors are 57.34 and technical related factors are 60.85. This comparative study will help users to select best one among these three tools according to their requirements.

\section{REFERENCES}

1. Mohammad Imran, Dr. Mohamed A.Hebaishy \& Dr. Abdullah Shawan Alotaibi, "Comparative Study of QTP and Load Runner Automated Testing Tools and their Contributions to Software Project Scenario”, International Journal of Innovative Research in Computer and Communication Engineering ,Vol. 4, Issue 1, pp.457466,2016.

2. Krutika Kamble \& Jyoti Kharade, "Quantitative Analysis of Manual and Automation Testing and Comparative Study of Selenium and Load Runner Automated Testing Tools”, International Journal of Innovative Research in Computer and Communication Engineering, Vol. 4, Issue 5, pp.9577-9583, 2016.

3. Sanjeev Gupta, Sunil Kumar, Chirag Saxena, "Review Paper on Comparison of Automation Testing Tools Selenium and QTP”, MIT International Journal of Computer Science and Information Technology, ISSN 2230-7621,Vol. 5, No. 2, pp. 55-57,2015.

4. Amit P. Raut, Garima A. Chudiwale \& Priyanka A. Kawale,” A Survey and Study of Software Testing Tools”, International Journal of Research in Science \& Engineering, Special Issue: Techno-Xtreme, pp.212-217, 2016.

5. Shalini Gautam \& Bharti Nagpal, "Descriptive Study of Software Testing \& Testing Tools”, International Journal of Innovative Research in Computer and Communication Engineering, Vol. 4, Issue 6, pp.10288-10295, 2016.

6. Priyanka Rathi \& Vipul Mehra, "Analysis of Automation and Manual Testing Using Software Testing Tool”, International Journal of Innovations \& Advancement in Computer Science, ISSN 2347 - 8616, Vol. 4, Special Issue, pp.710-713, 2015.

7. Rifa nizam khan \& Shobhit gupta, "Comparative Study of Automated Testing Tools: rational functional tester, quick Test professional, silk test and Load runner”, International Journal of Advanced Technology in Engineering and Science, Vol.3, special issue no.01, pp.167-172, 2015.

8. R. Beulah and Dr. M. Soranamageswari, "Performance and Comparative Study of Functionality Testing Tools: Win Runner and QTP in IT World”, International Journal of Advanced Research in Computer and Communication Engineering, ISSN (Online) 2278-1021, Vol. 4, Issue 7, pp. 296-301, 2015.

9. Mohamed Monier \& Mahmoud Mohamed El-mahdy, "Evaluation of Automated Web Testing Tools", International Journal of Computer Applications Technology and Research, ISSN:- 2319-8656, Vol. 4, Issue 5, pp.405-408, 2015.

10. Shaveta, Sachin kumar, Nitika \& Snehlata, "Comparative Study of Automated Testing Tools: Quick Test Pro and Load Runner", International Journal of Computer Science and Information Technologies, ISSN:0975-9646,Vol. 3 (4) , pp.4562-4567, 2012.

11. Preeti Yadav \& Ajay Kumar, "An Automation Testing using Selenium Tool”, International Journal of Emerging Trends \& Technology in Computer Science (IJETTCS) ,ISSN 22786856, Vol.4, Issue 5(2), pp.68- 71, 2015.

12. Tarik Sheth \& Dr. Santosh Kumar Singh, "Software Test Automation- Approach on Evaluating Test Automation Tools”, International Journal of Scientific and Research Publications, ISSN 2250-3153, Vol. 5, Issue 8, pp.1-3, 2015.

13. V. Maheshwari and M. Prasanna, "Generation of Test Case using Automation in Software Systems - A Review", Indian Journal of Science and Technology, Vol 8(35), pp.1-9, 2015.

14. P.Mani \& M.Prasanna, "Test Case Generation for Embedded System Software Using UML Interaction Diagram”, Journal of Engineering Science and Technology, 12 (4), pp.860-874, 2017.

15. Richard E.Fairley "Software Engineering Concepts", McGraw-Hill Education(India) Pvt Limited, 2001. 